WORD COUNT: 4,650 WORDS

11

RESUBMITTED TO: JOURNAL OF SENSORY STUDIES

13

14 DATE: $30^{\text {th }}$ April 2018

15

16

17

18 Correspondence to: Charles Spence, Department of Experimental Psychology, University of 19 Oxford, Oxford, OX1 3UD, UK.

20

21 E-mail: charles.spence@psy.ox.ac.uk 
ABSTRACT

25 The last 500 years or so has seen a phenomenal increase of interest in piquant/spicy food around the world. In this review, the latest research documenting the crossmodal influences on the perception of oral piquancy/spiciness that have been established to date are summarized: Everything from the color of the foodstuff through the color of the plateware on which that food is served has been found to influence both the expected and experienced piquancy/spiciness of food. Furthermore, certain musical parameters have also been shown to enhance perceived piquancy of the food in a restaurant setting. By contrast, spicy smells have not, as yet, attracted anything like as much research interest from the scientific community. Intriguingly, many of the crossmodal influences on piquancy/spiciness that have been documented to date appear to be more pronounced when the actual experience on tasting the food is close to the pre-consumption expectations. And while many of the crossmodal effects in this area appear to mirror those found previously for basic taste and flavor stimuli, there is a sense in which the broader range of intensities of sensation experienced in relation to chilli/capsaicin may mean that crossmodal influences are somewhat different in this case.

KEYWORDS: Chemesthesis; Oral Burn; Multisensory; Vision; Crossmodal; Sounds Spicy. 
44 Piquancy/spiciness is a highly-desirable food attribute. In fact, chiles are eaten by 1 in 4 of us 45 every day.

46 As yet, however, it has not attracted anything like the research interest that the basic tastes 47 have.

48 This review draws attention to the multisensory factors (including color, sound, etc.) that 49 have recently been shown to modulate the experienced piquancy/spiciness of a dish.

50 Given its widespread appeal, gaining a better understanding of this most desirable of oral 51 sensations is likely to benefit food providers. 
The perception of spiciness (or piquancy; these terms will be used interchangeably) in a dish, while widely liked by many people around the world, has not received anything like as much research interest from the multisensory or, for that matter, sensory science, communities as have, for instance, the basic tastes (sweet, sour, salty, bitter, and umami) or common flavor experiences. This seeming neglect is somewhat surprising given that hot pepper (red or green) of the genus Capsicum (family Solanaceae) is one of the world's most widely-used spices, found in thousands of recipes, and also sometimes eaten as a stand-alone item/dish. Indeed, according to Cordell and Araujo (1993), one in four people on the planet eat chile on a daily basis. This spicy fruit has, in other words, grown phenomenally in terms of its popularity around the world, since its 'discovery' by Columbus (Fernández-Armesto, 1991). The trigeminal piquancy of chilli has, over the centuries, been incorporated into the cuisines of many countries/cultures. In fact, according to Pavia (2018), the consumption of chilli peppers more than doubled between 1980 and 2013. At the same time, however, researchers still cannot seem to agree as to whether trigeminal inputs should be incorporated as part of the experience of flavor or not (see Gorman, 2010; Green, 1996; and Spence, Smith, \& Auvray, 2015, for a review). This despite the fact that almost three decades ago, Lawless (1989) described trigeminal stimulation as 'the forgotten flavor sense.'

From a multisensory perspective, it might be expected, given the potentially painful oral burn associated with high levels of piquancy, that such highly-arousing stimuli would dominate over other, less painful, sensory inputs (cf. Van Damme, Crombez, \& Spence, 2009); One might, for example, believe that capsaicin-related sensations would be somewhat less subject to the kinds of visual dominance effects (e.g., of color over taste and flavor perception) that have been documented elsewhere in the literature (see Spence, 2015, for a review). Over the last few years, however, a growing body of empirical research has started to demonstrate that our perception of, and behavior around, piquant/spicy food is subject to many of the same crossmodal influences as have been shown to affect our experiences of basic taste and flavor stimuli (e.g., Shermer \& Levitan, 2014; Tu, Yang, \& Ma, 2016; Wang, Keller, \& Spence, 2017; Xu \& Labroo, 2014). [One of the problems, though, for researchers in this area, is that there is currently no adequate animal model, given that the latter do not spice their food (Sherman \& Billing, 1999).]

The burn of capsaicin is estimated on the Scoville Scale, in units known as Scoville Heat Units (Scoville, 1912). The amount by which a sample has to be diluted before the presence 
of capsaicin can no longer be tasted by a majority of tasters provides the SHU (values go up to the millions for the hottest chillies; Gorman, 2010). To the extent that the perception of piquancy is subject to crossmodal influences, e.g., from food and plateware color cues (Shermer \& Levitan, 2014), from the use of spicy 'sonic seasoning' (Morley, 2017; Wang, Keller, \& Spence, 2017), etc., one might expect that the Scoville Scale would not provide an especially accurate indicator of the likely burn perceived associated with a given piquant/spicy stimulus. That said, the crossmodal influences on the perception of piquancy/spiciness that have been documented to date, while significant in their own right (see below), tend to pale into insignificance, when compared to the full range of SHUs widely consumed in food by humans. And ultimately, while capsaicin may well be the beststudied of chemesthetic trigeminal stimulants, it has nevertheless still attracted far less research interest than any of the other basic tastes. This is all rather surprising given the chile plants global popularity (Cordell \& Araujo, 1993).

\section{Crossmodal contributions to the perception of piquancy/spiciness}

It is important to realize that we rarely consume a food without first looking at it and perhaps also smelling it too. The resulting visual and orthonasal olfactory cues typically set expectations regarding the likely taste/flavor, and presumably also any possible oral burn, that is likely to ensue on consuming the food so inspected (see Piqueras-Fiszman \& Spence, 2015, for a review). A growing body of gastrophysics research now shows that a number of cues (both product intrinsic and product-extrinsic) influence the expected taste, aroma, flavor of the food we eat (Spence, 2017). Below, the results of this emerging research, documenting the impact of these non-trigeminal cues on the perception of piquancy, are reviewed.

\section{Visual contributions to the expectation/perception of piquancy/spiciness in food}

In terms of the role of visual cues on the expectation and perception of piquancy, and specifically color's influence on taste ratings, the first thing to note is that the color red is associated with heat (in terms of temperature; see Ho, Van Doorn, Kawabe, Watanabe, \& Spence, 2014; Michael, Galich, Relland, \& Prud'hon, 2010; Spence, Wan, Woods, Velasco, Deng, Youssef, \& Deroy, 2015). Furthermore, Shermer and Levitan (2014) have shown that the color red is also associated with piquancy (though see Scoville, 1912). In particular, Shermer and Levitan reported that the intensity (saturation) of red coloring in a salsa (varied 
over five levels) affected people's ratings of the expected spiciness of salsas viewed on a monitor. Specifically, increasing the redness (saturation) of the salsa led to a significant increase in the expected piquancy of the dish. Subsequently, these researchers went on to demonstrate that expected spiciness exerted a significant influence over the rated level of spiciness on tasting the salsa itself.

In particular, the participants in a second experiment tasted a mild and a more piquant salsa that each had one of two levels of redness both sighted and when blindfolded. For the spicier of the two salsas, the less intensely red one was rated as significantly less piquant that the redder version. However, both blindfolded ratings matched the sighted redder salsa (see Figure 1). Intriguingly, though, the change in visual appearance had no effect on ratings of the piquancy of the milder of the two salsas. These results therefore demonstrate that the color of a food itself (a product-intrinsic cue) can influence both the expected and perceived spiciness of the dish.

Figure 1. Results of Shermer and Levitan's (2014, Experiment 3) study of the impact of color intensity on ratings of two salsas tasted under normal viewing conditions and when blindfolded (note that a 7-point response scale was used.) [Figure reprinted with permission.]

In a way, this result is kind of surprising given the range of colors that ripe fresh chillies actually attain: According to Miller and Harrisson (1991), for instance, ripe fresh chilies end up red, yellow, orange, and brown in color. This might all be taken to suggest that the colors we bring to mind when asked to think of the color we associate with spicy taste is bright red (see Saluja \& Stevenson, in press) - i.e., the other chile colors are simply less available to us.

$\mathrm{Tu}$ et al. (2016) conducted a series of three experiments in which Chinese participants evaluated the expected/tasted piquancy of a sample of aromatic spicy bean curd. When presented on a red or yellow plate, the participants expected the sample to taste significantly spicier (by around 10\%) than when presented on a green or white plate instead. The results of a second experiment revealed that the background color of the plate exerted a significant impact over perceived spiciness as well. Specifically, participants rated the bean curd samples ("slighty spicy" and "severely spicy") as tasting almost 20\% spicier when sampled from a red plate than from a white plate. Intriguingly, the impact of plate color was numerically 
somewhat larger (1.76 difference on a 9-point scale) than that associated with actually tasting different spicy tofus described by the producer as "slightly" and "severely" spicy (a difference of 1.26). Finally, in a third experiment, both expected and then tasted spiciness were assessed within the same group of participants, with the spicy bean curd once again being served on either a red or white plate. The results and supporting data analysis from this final study revealed that the spiciness expectations set by the background plate color mediated the impact on the rated spiciness of the bean curd (see Figure 2). Interestingly, however, people's visual expectations did not appear to tell the whole story with regard to the perceived spiciness of the bean curd when tasted, as there was also a direct effect of plate colour on participant's spiciness ratings too.

Figure 2. Mediation model for color, spiciness expectation, and actual perceived spiciness based on Tu et al.'s (2016; Experiment 3) results. The negative value means that when compared with the red plate (if the value of red equals zero), the predicted value of spiciness expectation or actual perceived spiciness will be lower on the white plate (if the value of white equals one); $* \mathrm{P}<.05 ; * * \mathrm{P}<.001$. [Figure reprinted with permission from Tu et al. (2016).]

Researchers have also reported that the brightness of the ambient lighting influenced people's choices concerning the spiciness of the chicken wings they ordered (Xu \& Labroo, 2014). The participants in this particular study chose significantly spicier sauces for their wings in rooms that were more brightly-lit, as compared to rooms that were dimly-lit. Chicken wings provide a particularly appropriate stimulus for this kind of study given that they are often sold with a range of possible levels of spiciness.

\section{Auditory contributions to the expectation/perception of piquancy/spiciness in food}

The research now shows that playing specially-composed 'spicy' music can make a spicy salad taste spicier (Wang et al., 2017). In particular, Wang and her colleagues conducted a series of studies designed to investigate the auditory parameters that correspond to the experience of spiciness/piquancy in food. They also assessed whether such crossmodal correspondences exerted perceptual consequences over the rated spiciness of actual dishes 
tested/tasted in a naturalistic restaurant setting. Wan et al. first conducted an online study to determine the acoustical/musical parameters that best match (or correspond) to spiciness. The results suggested that people associated spiciness with high pitch, fast tempo, and a distorted timbre. These crossmodal correspondences were then used to compose a spicy soundscape that was incorporated into Wang et al.'s subsequent experiments.

Figure 3. A dish created by chef Deb Paquette and served to diners in her restaurant Etch in Nashville Tennessee (http://www.etchrestaurant.com/). How spicy would you guess this dish was going to taste? Research by Wang et al. (2017) suggests it doesn't taste as spicy as you might think.

Wang et al.'s (2017) between-participants Experiment 2, was conducted in a restaurant in order to test the effect of different background sound conditions on participants' expected and actual ratings of a novel restaurant dish consisting of a piece of ancho chilli dusted butternut squash tempura with brie, pear, mushrooms and salad leaves, topped with a sour-spicy dressing, spicy pepitas, and spiced chocolate sauce (see Figure 3). Four sound conditions were evaluated: a spicy soundtrack constructed to incorporate the musical elements identified in the first study), a sweet soundtrack, white noise, and silence. The expected spiciness of the dish was significantly higher for those in the spicy soundscape group as compared to the other three groups. However, no significant differences were observed in terms of people's actual taste ratings. A contributing factor to this latter null result, however, may well have been the large disparity between the participants' expectations of spiciness and the actual (mild) spiciness of the test dish itself.

Figure 4. Results of participants' ratings of the taste of salsa in Wang et al.'s (2017; Experiment 3), in all four sound conditions. Error bars represent the standard error of the means. Asterisks denote statistical significance $\left({ }^{*} \mathrm{p}\right.$ $<$.05). (10-point response scales used.) [Figure reprinted with permission from Wang et al. (2017).] 
211 To follow-up, Wang et al. (2017) conducted a further study with a spicier food sample (salsa) and the same sound conditions (with the soundtracks being presented over headphones). This time, the results revealed that the rated spiciness of the salsa was significantly higher (in fact, ratings were almost $20 \%$ higher) in the spicy soundtrack condition than in the other sound conditions (see Figure 4). Finally, Wang et al. conducted a study using both mild and hot salsa (Experiment 4) that highlighted a significant interaction between the sound condition and the spiciness level of the stimuli, consistent with the assimilation-contrast model of consumer disconfirmation of expectation (Deliza \& MacFie, 1996; see Piqueras-Fiszman \& Spence, 2015, for a review). Namely, only the spicier of the two salsa samples was affected by the musical accompaniment (see Figure 5). Taken together, then, these results demonstrate that a soundscape with auditory attributes corresponding to spiciness can enhance the perception of spiciness in foods, likely via a mechanism of induced sensory expectations.

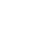

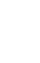

\section{Figure 5. Participants' ratings of the spiciness of the two salsas in Wang et} al.'s (2017; Experiment 4), as a function of the sound conditions (spicy soundtrack vs. silence). Error bars represent the standard error of the means. Asterisks denote statistical significance $(* \mathrm{p}<.05$; a 10 -point response scales used). [Figure reprinted with permission from Wang et al. (2017).]

\section{Olfactory contributions to the expectation/perception of piquancy/spiciness in food}

In terms of olfactory cues to spiciness, the relevant question here is whether there are 'spicy smells'? That is, aromas that, if added to a dish, might make people rate it as tasting spicier. Researchers have, after all, already documented various aromas that are associated with many of the basic tastes (Stevenson \& Boakes, 2004). Aromas such as caramel, vanilla, and strawberry are all rated as smelling 'sweet' (Stevenson, Boakes, \& Prescott, 1998). Salty, sour, bitter, and even umami-enhancing smells have all now been documented too (e.g., Seo, Iannilli, Hummel, Okazaki, Buschhüter, Gerber, Krammer, van Lengerich, \& Hummel, 2013). Given such findings, one might reasonably have expected that certain trigeminal irritants like, for example, capsaicin would also be associated with certain characteristic food aromas. Capsaicin does not only stimulate the trigeminal nerve (Viana, 2011), but also the 
glossopharyngeal and vagus nerves as well (at least according to Rentmeister-Bryant \& Green, 2007). However, I am not aware of any such spicy aromas having being reported/studied in the literature as yet (though see Herderich, Siebert, Parker, Capone, Jeffery, Osidacz, \& Francis 2012; and Labbe, Gilbert, \& Martin, 2008, for research in this general direction). Who knows whether such spicy smells exist, or whether the fact that capsaicin is a fairly pure chemesthetic stimulant means that they won't be found (perhaps such 'tasty' smells only occur for those chemosensory stimuli having a gustatory component)? That said, people do sometimes respond that the cooking is spicy on experiencing nasal trigeminal irritation when entering the kitchen when someone is cooking spicy food. Alternatively, however, one might wonder whether the problem is rather that chilli is added to so many foods nowadays that it is hard to determine a characteristic aroma with which it is paired. But then, if that were the reason, surely the same argument could be put forward for sweetness or any other basic tastant. Presumably what is more important than the number of aromas that are experienced together with a given taste, or oral sensation, is that a given aroma regularly co-occurs with a specific tastant. In this regard, chilli would not then seem to be unique. Nevertheless, given the continued global enthusiasm for chilli, this would seem to be one area where additional research is sorely needed

\section{Descriptive contributions to the expectation/perception of piquancy/spiciness in food}

One other potentially relevant factor here that it is worth thinking about is the verbal or written description given to a dish. Just consider how the likely spiciness of a dish in an Indian or Asian restaurant, say, is often flagged-up on the menu by the number of chilli symbols next to the name or description of the dish. Indeed, a substantial body of research now shows that telling people that a solution will taste very bitter (or very sweet) versus suggesting that it will not taste bitter (or sweet) at all has been shown to modulate both subjective ratings of the intensity of that taste, as well as neural activity as early as primary gustatory cortex (e.g., Nitschke, Dixon, Sarinopoulos, Short, Cohen, Smith, Kosslyn, Rose, \& Davidson, 2006; Woods, Lloyd, Kuenzel, Poliakoff, Dijksterhuis, \& Thomas, 2011). Would the same be true in the case of piquancy? That is, would a curry be rated as tasting spicier should it erroneously be flagged-up as tasting especially spicy? It would seem entirely possible, but this is another of the areas where further research is still most definitely needed. [One challenge, though, for any kind of research in this area being the long-tasting burn makes the running of a repeated measures experimental designs somewhat challenging 
(practically-speaking) in a way that one simply doesn't really need to worry about when it comes to the other basic taste and flavor stimuli.]

\section{Crossmodal influence of capsaicin on perception/behavior}

The focus in the preceding sections has been on how the other senses affect our perception of, and behavior around, piquancy in food. However, one can also ask the opposite question too: Namely, how does the experience of piquancy influence our perception of, and/or behavior around other stimuli (such as, for instance, music). There is, though, little research to go on to date. In this regard, it is nevertheless interesting to consider the case of the Danish National Chamber Orchestra who played part of a musical composition (Tango Jalouise), before stopping to eat the world's then-hottest chilli. They then resumed their rendition as the slowacting heat of the chilli started to take effect (e.g., Berman, 2014). The idea was that the physiological arousal induced by the chilli might exert a crossmodal influence on the orchestra's rendition. While there was no formal assessment of the consequences of capsaicin (nor any control group), it is nevertheless clear to anyone who has seen the video of this event that oral piquancy affected the musician's performance. Nevertheless, the more fundamental question of how the consumption of chillies, and the oral burn that is induced, affect our responses to other stimuli is an interesting topic for future research.

\section{Conclusions}

While there is currently far less published research on crossmodal influences on the perception of, and behavior around spicy/piquant foods than for many other non-trigeminal tastants, the emerging research (all published within the last few years) clearly suggests that many of the same factors, such as the color of the product/plateware, ambient lighting, and spicy sonic seasoning can all influence people's expectations, and subsequently, ratings/perception of the spiciness of foods as diverse as salsa and tofu. While the perception of spiciness/piquancy in food is in some sense different from our experience of basic tastes and flavors (and indeed some question whether trigeminal inputs should be incorporated into our definition of constitute flavor senses, or merely be considered as a modulatory factor; see Spence et al., 2015), nevertheless, this sensation, traditionally associated with foods from more tropical climes, is subject to many of the same crossmodal influences (of food and background color, and also the ambiance - e.g., background lighting and music). 
That said, further research is still needed in order to determine whether or not there really are spicy smells that can bring out the piquancy of a dish. It would also be interesting to know whether the descriptions given to a dish also exert a significant influence over our experience of oral burn/heat in the way that has been shown for our perception of the basic tastes such as bitter. The findings of such research will hopefully enable flavour scientists to address the question of whether multisensory interactions with capsaicin are somehow different/special from the kinds of crossmodal interactions observed with basic tastes, aromas, and flavors.

\section{REFERENCES}

BERMAN, E. 2014. Watch the Danish National Chamber Orchestra perform after eating world's hottest chili peppers. Time, November $3^{\text {rd }}$. http://time.com/3555296/danish-nationalorchestra-chili-peppers/.

BILLING, J., and SHERMAN, P.W. 1998. Antimicrobial functions of spices: Why some like it hot. Quarterly Rev. Biol., 73, 3-49.

CORDELL, G.A., and ARAUJO, O.E. 1993. Capsaicin: Identification, nomenclature, and pharmacotherapy. Annual Pharmacotherapy, 27, 330-336.

DELIZA, R., and MACFIE, H.J.H. 1996. The generation of sensory expectation by external cues and its effect on sensory perception and hedonic ratings: A review. J. Sens. Stud., 2, $103-128$.

FERNÁNDEZ-ARMESTO, F. 1991. Columbus. Oxford, UK: Oxford University Press.

Gorman, J. 2010. A perk of our evolution: Pleasure in pain of chilies. The New York Times, September

$20^{\text {th }}$. http://www.nytimes.com/2010/09/21/science/21peppers.html?pagewanted=all.

GREEN, B.G. 1991. Temporal characteristics of capsaicin sensitization and desensitization on the tongue. Physiol. Behav., 49, 501-505.

GREEN, B. 1996. Chemesthesis: Pungency as a component of flavor. Trends Food Sci. Technol., 7, 415-420.

GREEN, B.G. 2016. Introduction: what is chemesthesis? In S.T. MCDONALD, D.A. BOILLIET, and J.E. HAYES (Eds.), Chemesthesis: Chemical touch in food and eating (pp. 1-31). Oxford, UK: Wiley-Blackwell.

HERDERICH, M.J., SIEBERT, T.E., PARKER, M., CAPONE, D.L., JEFFERY, D.W., OSIDACZ, P., and FRANCIS I.L. 2012. Spice up your life: Analysis of key aroma compounds in Shiraz. ACS Symposium Series (Flavor Chemistry of Wine and Other Alcoholic Beverages), 1104, 3-13.

HO, H.-N., VAN DOORN, G.H., KAWABE, T., WATANABE, J., and SPENCE, C. 2014. Colour-temperature correspondences: When reactions to thermal stimuli are influenced by colour. PLoS ONE, 9:e91854. 
LABBE, D., GILBERT, F., and MARTIN, N. 2008. Impact of olfaction on taste, trigeminal, and texture perceptions. Chemosens. Percept., 1, 217-226.

LAWLESS, H. 1989. Pepper potency and the forgotten flavor sense. Food Technol., 11, 52, $57-58$.

MICHAEL, G.A., GALICH, H., RELLAND, S., and PRUD'HON, S. 2010. Hot colors: The nature and specificity of color-induced nasal thermal sensations. Behav. Brain Res., 207, $418-428$.

MILLER, M., and HARRISSON, J. 1991. The great chile book. Berkeley, CA: Ten Speed Press.

MORLEY, K. 2017. Music makes curries taste 10pc spicier, scientists find. The Daily Telegraph, March $12^{\text {th }}$. http://www.telegraph.co.uk/news/2017/03/12/music-makes-curriestaste-10pc-spicier-scientists-find/.

NITSCHKE, J.B., DIXON, G.E., Sarinopoulos, I., SHORT, S.J., COHEN, J.D., SMITH, E.E., KOSSLYN, S.M., ROSE, R.M., and DAVIDSON, R.J. 2006. Altering expectancy dampens neural response to aversive taste in primary taste cortex. Nature Neurosci., 9, 435442.

PIQUERAS-FISZMAN, B., and SPENCE, C. 2015. Sensory expectations based on productextrinsic food cues: An interdisciplinary review of the empirical evidence and theoretical accounts. Food Qual. Pref., 40, 165-179.

RENTMEISTER-BRYANT, H., and GREEN, B.G. 1997. Perceived irritation during ingestion of capsaicin or piperine: Comparison of trigeminal and non-trigeminal areas. Chem. Senses, 22, 257-266.

ROZIN, P. 1987. Psychobiological perspectives on food preferences and avoidances. In M. HARRIS and E.B. ROSS (Eds.), Food and evolution: Toward a theory of human food habits (pp. 181-205). Philadelphia, PA: Temple University Press.

ROZIN, P. 1990. Getting to like the burn of chili pepper: Biological, psychological, and cultural perspectives. In B.G. GREEN, F.R. MASON, and M.R. KARE (Eds.), Chemical senses, Vol 2: Irritation (pp. 217-228). New York, NY: Dekker.

SALUJA, S., and STEVENSON, R.J. in press. Cross-modal associations between real tastes and colors. Chem. Senses.

SCOTT, F. 2016. Flaming idiot! Crazy moment prankster screams in pain after bathing himself (and dunking his head) in 1,250 bottles of hot chilli sauce. Daily Mail Online, August $26^{\text {th }}$. http://www.dailymail.co.uk/news/article-3760515/Crazy-moment-prankster-screams-painbathing-dunking-head-1-250-bottles-hot-chilli-sauce.html.

SCOVILLE, W.L. 1912. Note on capsicums. J. Am. Pharmaceut. Assoc., 1, 453-454.

SEO, H.-S., Iannilli, E., HUMMEL, C., OKAZAKI, Y., BUSCHHÜTER, D., GERBER, J., KRAMMER, G.E., VAN LENGERICH, B., and HUMMEL, T. 2013. A salty-congruent odor enhances saltiness: Functional magnetic resonance imaging study. Hum. Brain Mapp., 34, 62-76.

SHERMAN, P.W., and BILLING, J. 1999. Darwinian gastronomy: Why we use spices. Spices taste good because they are good for us. BioScience, 49, 453-463.

Shermer, D.Z., and LEVITAN, C.A. 2014. Red hot: The crossmodal effect of color intensity on piquancy. Multisens. Res., 27, 207-223. 
SPENCE, C. 2012. Auditory contributions to flavour perception and feeding behaviour. Physiol. Behav., 107, 505-515.

SPENCE, C. 2015. On the psychological impact of food colour. Flavour, 4:21.

SPENCE, C. 2017. Gastrophysics: The new science of eating. London, UK: Viking Penguin.

SPENCE, C. 2018. Why is piquant/spicy food so popular? Int. J. Gastron. Food Sci.

SPENCE, C., SMITH, B., and AUVRAY, M. 2015. Confusing tastes and flavours. In D. STOKES, M. MATTHEN, and S. BIGGS (Eds.), Perception and its modalities (pp. 247274). Oxford, UK: Oxford University Press.

SPENCE, C., WAN, X., WOODS, A., VELASCO, C., DENG, J., YOUSSEF, J., and DEROY, O. 2015. On tasty colours and colourful tastes? Assessing, explaining, and utilizing crossmodal correspondences between colours and basic tastes. Flavour, 4:23.

STEVENSON, R.J., and BOAKES, R.A. 2004. Sweet and sour smells: Learned synaesthesia between the senses of taste and smell. In G.A. Calvert, C. Spence, and B.E. Stein (Eds.), The handbook of multisensory processing (pp. 69-83). Cambridge, MA: MIT Press.

STEVENSON, R.J., BOAKES, R.A., and PRESCOTT, J. 1998. Changes in odor sweetness resulting from implicit learning of a simultaneous odor-sweetness association: An example of learned synaesthesia. Learn. Motiv., 29, 113-132.

TÖRNWALL, O., SILVENTOINEN, K., KAPRIO, J., and TUORILA, H. 2012. Why do some like it hot? Genetic and environmental contributions to the pleasantness of oral pungency. Physiol. Behav., 107, 381-389.

TU, Y., YANG, Z., and MA, C. 2016. The taste of plate: How the spiciness of food is affected by the color of the plate used to serve it. J. Sens. Studies, 31, 50-60.

VAN DAMME, S., CROMBEZ, G., and SPENCE, C. 2009. Is the visual dominance effect modulated by the threat value of visual and auditory stimuli? Exp. Brain Res., 193, 197-204.

VIANA, F. 2011. Chemosensory properties of the trigeminal system. ACS Chemical Neurosci., 2, 38-50.

WANG, Q.(J.), KELLER, S., and SPENCE, C. 2017. Sounds spicy: Enhancing the evaluation of piquancy by means of a customised crossmodally congruent soundtrack. Food Qual. Pref., $58,1-9$.

WOODS, A.T., LLOYD, D.M., KUENZEL, J., POLIAKOFF, E., DIJKSTERHUIS, G.B., and THOMAS, A. 2011. Expected taste intensity affects response to sweet drinks in primary taste cortex. Neuroreport, 22, 365-369.

XU, A.J., and LABROO, A.A. 2014. Incandescent affect: Turning on the hot emotional system with bright light. J. Consumer Psychol., 24, 207-216. 